Article

\title{
An All-Solid-State Lithium Metal Battery Based on Electrodes-Compatible Plastic Crystal Electrolyte
}

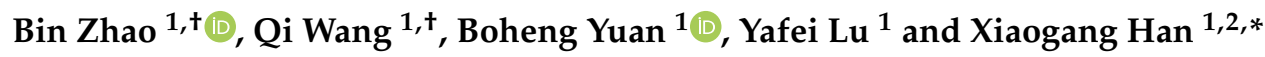 \\ 1 State Key Laboratory of Electrical Insulation and Power Equipment, School of Electrical Engineering, \\ Xi'an Jiaotong University, Xi'an 710049, China; zhaobin87@xjtu.edu.cn (B.Z.); \\ wq4116005096@stu.xjtu.edu.cn (Q.W.); yuan980808@stu.xjtu.edu.cn (B.Y.); luyafei0126@stu.xjtu.edu.cn (Y.L.) \\ 2 Key Laboratory of Smart Grid of Shanxi Province, Xi'an 710049, China \\ * Correspondence: xiaogang.han@xjtu.edu.cn \\ + B.Z. and Q.W. contributed equally to this work.
}

Citation: Zhao, B.; Wang, Q.; Yuan, B.; Lu, Y.; Han, X. An All-Solid-State Lithium Metal Battery Based on Electrodes-Compatible Plastic Crystal Electrolyte. Energies 2021, 14, 6946. https://doi.org/10.3390/en14216946

Academic Editor: Xia Li

Received: 6 September 2021

Accepted: 6 October 2021

Published: 22 October 2021

Publisher's Note: MDPI stays neutral with regard to jurisdictional claims in published maps and institutional affiliations.

Copyright: () 2021 by the authors. Licensee MDPI, Basel, Switzerland. This article is an open access article distributed under the terms and conditions of the Creative Commons Attribution (CC BY) license (https:// creativecommons.org/licenses/by/ $4.0 /)$.

\begin{abstract}
Solid-state plastic crystal electrolytes (SPCEs) have attracted much attention due to their high ionic conductivity at room temperature and polymer-like plasticity. Herein, we made a $\mathrm{LiFePO}_{4}|| \mathrm{Li}$ solid state battery based on SPCEs. A SPCE film is made up of glass fiber, succinonitrile (SN), lithium bis (triflu-romethanesulphonyl) imid (LiTFSI), and $\mathrm{LiNO}_{3}$. Glass fiber is introduced to improve the mechanical property, and $\mathrm{LiNO}_{3}$ served as an additive to stabilize electrolyte/ Li interface. The SPCE film delivers a high ionic conductivity of $7.3 \times 10^{-4} \mathrm{~S} \mathrm{~cm}^{-1}$ at room temperature and has excellent stability with Li-metal anode. SPCE is also infused into cathode electrode and used as the interface with cathode particles, which can access a large interface contact area and deform reversibly with volume change. The $\mathrm{LiFePO}_{4} \mid$ | Li solid state battery based on SPCE can work well at ambient temperature, which shows a high initial specific capacity of $121.4 \mathrm{mAh} \mathrm{g}^{-1}$ and has $86.9 \%$ retention after 90 cycles at $0.5 \mathrm{C}$.
\end{abstract}

Keywords: plastic crystal; succinonitrile; solid-state batteries; electrode compatible

\section{Introduction}

Li-ion batteries have gained great success for commercial applications [1,2]. Though many efforts have been paid on the development of new cathode and anode materials with high energy and power density [3-6], the energy density of traditional Li-ion batteries cannot meet the practical requirements. So, the ever-increasing demand for higher energy densities has promoted the research using lithium metal as anode electrode [7]. However, the development of Li-metal batteries using traditional liquid electrolyte is plagued by the side reaction between electrolyte and lithium metal and the growth of lithium dendrites [8,9]. In this respect, all-solid-state lithium-metal batteries (ASSLMBs) with solid-state electrolytes (SSEs) are considered next generation battery technology to meet the needs of high energy density and safety [10].

SSEs can mainly be summarized in three types [11-13], inorganic solid electrolytes (ISEs), solid polymer electrolytes (SPEs), and composite polymer electrolytes (CPEs). Taking into account the brittle nature of ISE thin films, SPEs [14,15], including poly(ethylene oxide) (PEO), poly(acrylonitrile) (PAN), poly(methyl methacrylate) (PMMA), etc., are considered attractive for their lightweight property, high flexibility, and ease of processing. However, the practical application of SPEs on solid-state batteries (SSBs) is restricted by their low room-temperature conductivity. Taking the most studied system of PEO as an example, they show a low ionic conductivity of around $10^{-6} \mathrm{~S} \mathrm{~cm}^{-1}$ at ambient temperature and a low lithium-ion transfer number of about 0.2 [16], which is far from practical needed. To address this drawback, various strategies have been proposed, such as block copolymer crosslinking and addition of fillers or plasticizers to lower the glass transition temperature 
and improve ionic conductivity [11]. Even so, the ionic conductivity of SPEs at ambient temperature is still far from the need of practical room-temperature application.

In recent years, succinonitrile (SN) plastic crystals doped with Li salt have become one of the most interesting SSEs. The SN solid-state plastic crystal electrolytes (SPCEs) not only exhibit plastic properties similar to SPEs, but also show a Li-ion conductivity as high as $10^{-3} \mathrm{~S} \mathrm{~cm}^{-1}$ at $25^{\circ} \mathrm{C}$ due to the high diffusivity and solvating power of SN [17-19]. In solidstate batteries, a common method for a cathode electrode is to add solid electrolyte particles. However, in this strategy, there are only a small fraction of cathode particles contacting with solid electrolyte, which will cause large interface resistance. To address this problem, SPCEs have been studied as cathode/electrolyte interfaces to reduce the interfacial resistance due to its plastic nature [20-22]. On the other hand, due to the high room-temperature ionic conductivity, SPCEs have also been introduced into composite solid-state electrolyte system with improved ionic conductivity. [23-26] The greatest weakness of SPCEs as solid electrolyte is the incompatible of aliphatic nitriles with metallic lithium and solid-state batteries based on SPCEs mainly use $\mathrm{Li}_{4} \mathrm{Ti}_{5} \mathrm{O}_{12}$ as anode $[19,27]$. In this aspect, additives (e.g., FEC [28], $\mathrm{LiDFOB}$ [29], and $\mathrm{LiNO}_{3}$ [30]) have been introduced to stabilize the interface with Li metal.

In the above research, $\mathrm{SN}$ was used as part of solid composite electrolyte or electrode, since SN doped with LiTFSI system was suggested as an effective ambient temperature solid electrolyte, solid-state Li-metal batteries based on SPCE were not reported. In this paper, we proposed a solid-state Li-metal battery with solid SN electrolyte. A glass fiber membrane is used as a host to enhance the mechanical properties of SPCEs. The ionic conductivity of the SPCE film reaches $7.3 \times 10^{-4} \mathrm{~S} \mathrm{~cm}^{-1}$ at room temperature. Due to the addition of $\mathrm{LiNO}_{3}$, the symmetrical cell shows good stability at room temperature. For the cathode, SPCE was also applied for good solid-solid interface contact. $\mathrm{A} \mathrm{Li}_{\mid} \mathrm{LiFePO}_{4}$ battery was assembled, and it shows excellent cycle performance working at ambient temperature $\left(25^{\circ} \mathrm{C}\right)$.

\section{Materials and Methods}

\subsection{Preparation of SPCE}

The SN/LiTFSI mixed solution was prepared by heating a mixture of SN (99\%, Macklin) and LiTFSI (99\%, Aladdin) with a molar ratio of $19: 1$ at $60{ }^{\circ} \mathrm{C}$, and a clear solution was obtained. In addition, $1 \mathrm{wt} . \% \mathrm{LiNO}_{3}$ was added into the $\mathrm{SN} / \mathrm{LiTFSI}$ solution to stabilize the lithium metal interface. Glass fiber was soaked into the mixed solution for $12 \mathrm{~h}$ at $60^{\circ} \mathrm{C}$, and then cooled down to room temperature to get a SPCE film.

\subsection{Characterization and Electrochemical Measurements}

The morphology of samples was observed by scanning electron microscope (SEM, Phenom Pro X). XRD patterns were recorded using a Bruker D8 diffractometer, with $\mathrm{Cu}$ $\mathrm{K} \alpha$ radiation. The conductivity of $\mathrm{Li}$ ion of the SPCEs was conducted by electrochemical impedance spectroscopy (EIS) performed on biologic electrochemical station SP-500 with a frequency range from $7 \mathrm{MHz}$ to $100 \mathrm{mHz}$ at $60{ }^{\circ} \mathrm{C}, 50{ }^{\circ} \mathrm{C}, 40{ }^{\circ} \mathrm{C}, 30{ }^{\circ} \mathrm{C}$, and room temperature $\left(25^{\circ} \mathrm{C}\right)$, respectively. The electrochemical window of the samples was determined with a stainless steel (SS) ISPCE I Li cell using both electrochemical floating analysis and linear sweep voltammetry (LSV) under a sweep rate of $5 \mathrm{mV} \mathrm{s}^{-1}$ from 0 to $6 \mathrm{~V}$ at room temperature. The lithium-ion transference number $\left(\tau_{\mathrm{Li}^{+}}\right)$of SPCE film was evaluated by alternating current impedance combined with direct-current (DC) polarization with a DC voltage of $10 \mathrm{mV}$ with a Li ISPCE I Li cell. The stability of electrolyte with Li metal was carried out by Li plating/stripping experiments with a $\mathrm{Li} \mid$ | Li symmetric cell at a current density of $0.1 \mathrm{~mA} \mathrm{~cm}^{-2}$ performed on a LAND CT2001A testing system.

\subsection{Evaluation of Solid-State Batteries}

$\mathrm{LiFePO}_{4}$ cathode slurry was prepared by grinding $\mathrm{LiFePO}_{4}$ powder, carbon black, and polyvinylidene difluoride (PVDF) with mass fractions of 80,10 , and 10\%, respectively, 
followed by the addition of Methylpyrrolidone (NMP) solvent to obtain cathode slurry. The cathode slurry obtained was casted onto aluminum film and dried in a vacuum oven at $120^{\circ} \mathrm{C}$ for $12 \mathrm{~h}$. Cathode film was immerged into SPCE solution at $60^{\circ} \mathrm{C}$ for $12 \mathrm{~h}$; then, the well-infiltrated cathode and SPCE film were stacked together and cooled down to room temperature for a in situ solidification. Then, 2032-coin cells were assembled with Li foil as anode and SPCE film with $16 \mathrm{~mm}$ diameter as separator, and charging/discharging tests of batteries were performed on a LAND CT2001A testing system at room temperature.

\section{Results}

\subsection{Structural Characterization of SPCE}

The preparation process of SPCE is illustrated in Figure 1a. SPCE has a low melting point, and it is infiltrated into glass fiber matrix at $60^{\circ} \mathrm{C}$ to obtain a SPCE film (Figure $1 \mathrm{~b}$ ). When doped with Li salt, SN can still maintain solid state at $25^{\circ} \mathrm{C}$ (Figure 1c,d); however, the mechanical strength of $\mathrm{SN}$ becomes low, and it is almost impossible to prepare a pure SPCE film. Figure S1 shows the picture of pure SPCE, and it is too fragile to obtain electrolyte film. Glass fiber film is adopted in this work for concept, because it is widely used in battery devices, and it has a large pore volume. SEM image of glass fiber is shown in Figure 2a and S2; it has a good microfiber morphology, and the surface of the glass fibers are relatively smooth. Figure $2 b$ shows the morphology of the upper surface of SPCE film. Pores of glass fiber are filled with SN electrolyte, and the surface is very smooth. The SEM images of the cross-sections of SPCE film are shown in Figure 2c and S3. The thickness of SPCE film is about $143 \mu \mathrm{m}$, and many glass fibers can be seen on the cross-section surface. Thanks to the existence of glass fiber, the SPCE film has very good flexibility (Figure S4). From the cross-section image, we can further confirm that the inner of the glass fiber film was filled with SN electrolyte. The X-ray diffraction (XRD) patterns of pure SN and SPCE are demonstrated in Figure 2d. The diffraction peaks of the two samples all appear at $19.3^{\circ}$ and $27.5^{\circ}$, and there are no additional diffraction peaks. When doped with Li salt, the diffraction peak intensity of SPCE decreased compared with pure SN plastic crystal, which reflects the solvation effect of high polar SN in dissolving lithium salts. The decrease in crystallization indicates that the defect density increases, which leads to an increase in $\mathrm{Li}$ ion mobility.

a)

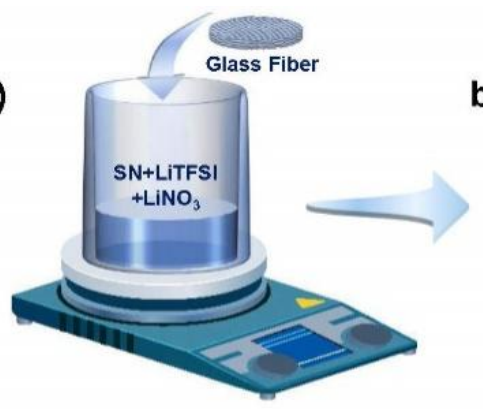

c)

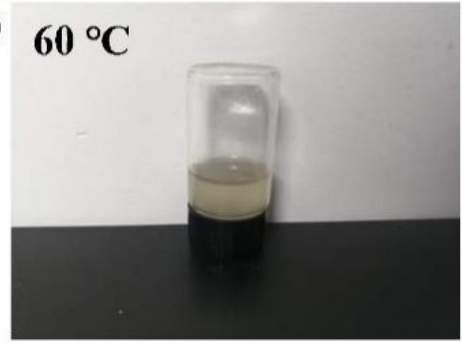

b)

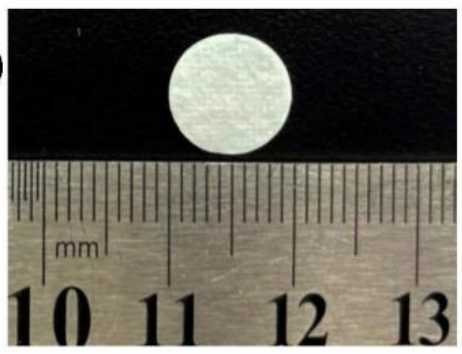

d)

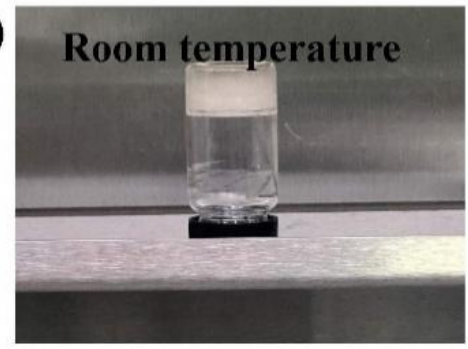

Figure 1. (a) Schematic diagram of the preparation of SPCE film. (b) Photo image of SPCE film. Photo images of the state of SPCE solution at (c) $60^{\circ} \mathrm{C}$ and (d) room temperature. 

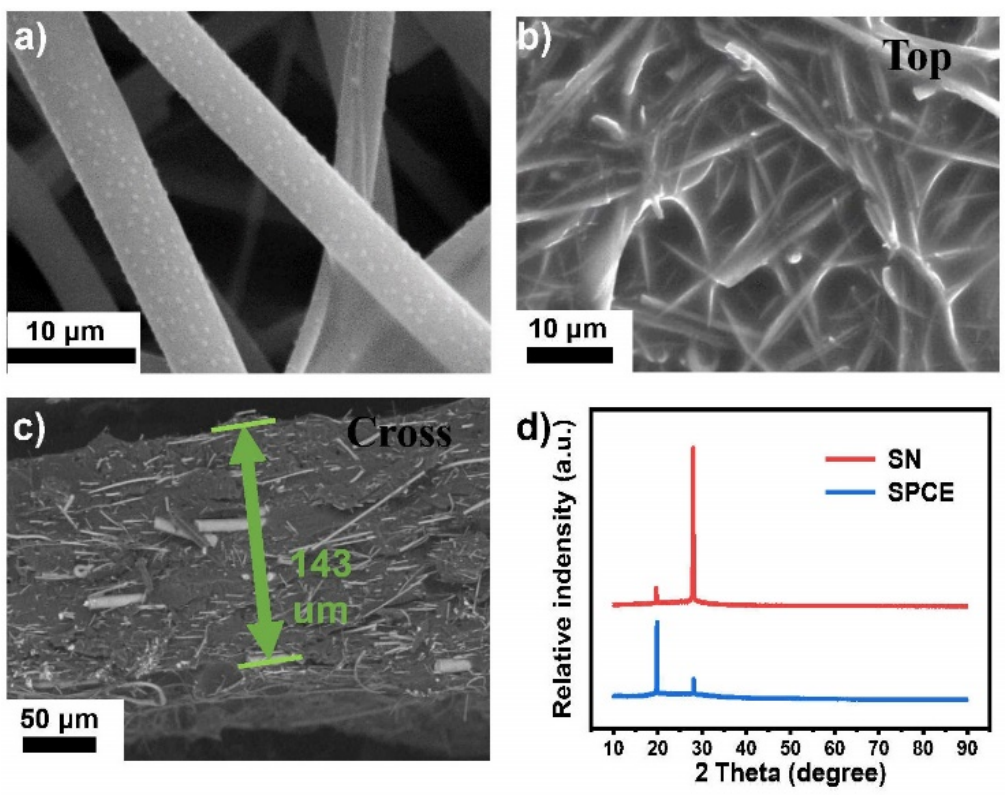

Figure 2. SEM images of (a) glass fiber film, the upper (b) and the cross-section (c) of SPCE film. (d) XRD patterns of SN and SPCE.

\subsection{Electrochemical Properties of SPCE Film}

SN plastic crystal displays a disorder structure, but molecules are ordered into a crystalline lattice. So, SN molecules have high local rotatory motions leading to high molecular mobility (illustrated in Figure S5); combined with the not too strong attraction with Li metal ions of nitrile groups, they can promote charge separation of Li salt and give a high ionic conductivity of $\mathrm{Li}^{+}$.

Figure 3a shows the electrochemical impedance spectra (EIS) of SPCE film at room temperature of $25^{\circ} \mathrm{C}$, and the ionic conductivity of SPCE film is as high as $7.3 \times 10^{-4} \mathrm{~S} / \mathrm{cm}$, which is mainly due to the high dielectric constant ( $\varepsilon-55)$, good solubility, and high molecular diffusivity of SN. EIS of SPCE film at various temperatures were also collected and shown in Figure 3b, and the impedance of SPCE film decreases with the increase in temperature, which can be fitted to Arrhenius equation $\sigma=\sigma_{0} \exp \left(-\frac{E_{a}}{k T}\right)$, where $\sigma$ is ionic conductivity, $\sigma_{0}$ is a pre-exponential factor, $E_{a}$ is the activation energy, and $k$ is Boltmann's constant. Arrhenius plot of SPCE film (Figure 3c) can clearly show the trend of impedance change with temperature, and the calculated activation energy $E_{a}$ for SPCE is $0.23 \mathrm{eV}$. The electrochemical window is also a critical parameter of a solid electrolyte; the electrochemical window of the SPCE is measured with electrochemical floating analysis [31] and linear sweep voltammetry (LSV) method. Electrochemical floating analysis provides a stringent test of the oxidative stability of SPCE film and the curve is shown in Figure 4a. The results show that at voltages below $4.7 \mathrm{~V}\left(\mathrm{vs} . \mathrm{Li} / \mathrm{Li}^{+}\right)$, the leakage current measured in the SPCE is small, and the oxidation process can be observed at $4.7 \mathrm{~V}$. The results of LSV reported in Figure S6 show the same result, that the electrochemical window of the SPCE is $4.6 \mathrm{~V}$. $\tau_{\mathrm{Li}^{+}}$of SPCE is measured with DC polarization and alternating current impedance technology, and it is calculated from the results shown in Figure $4 \mathrm{~b}$ by the Bruce-Vincent-Evans equation, giving 0.458 , which is higher than that of pure PEO electrolyte $(\sim 0.2)$. 


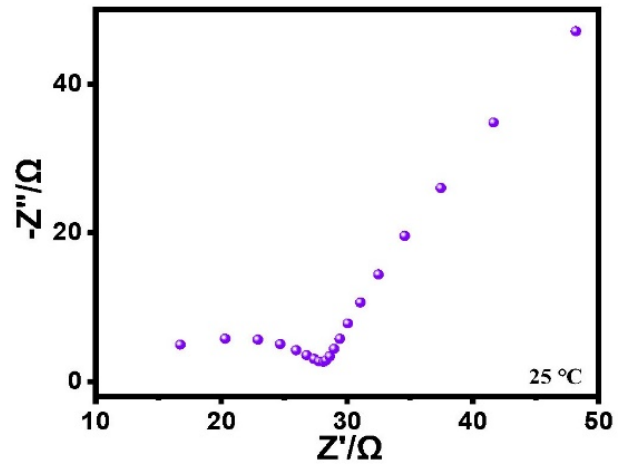

(a)

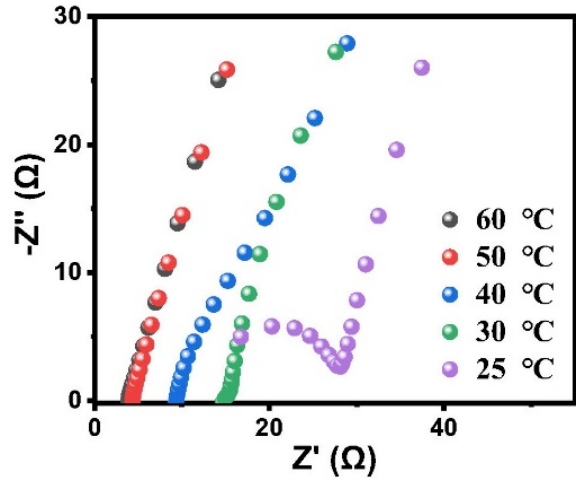

(b)

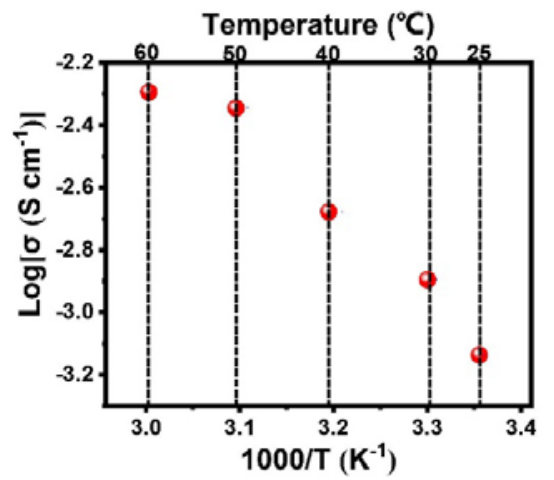

(c)

Figure 3. EIS test with SSI ISS cells. (a) Nyquist plot of SPCE at room temperature. (b) Nyquist and (c) Arrhenius plots of SPCE at different temperatures $\left(25,30,40,50\right.$, and $\left.60^{\circ} \mathrm{C}\right)$.
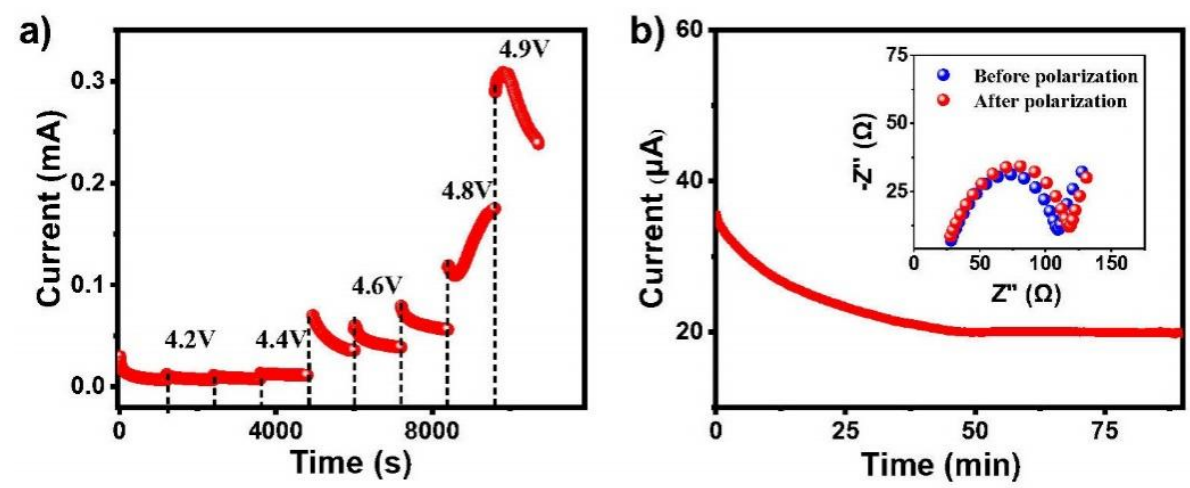

Figure 4. (a) Electrochemical floating analysis of SPCE with SS I I Li cell. (b) Current-time curve and EIS plots before and after polarization of SPCE with Li I I Li symmetric cell.

Generally, aliphatic nitrile of SN is incompatible with Li metal anode. To improve the interfacial compatibility of $\mathrm{SN}$ and $\mathrm{Li}$ metal, $\mathrm{LiNO}_{3}$ was introduced into the SPCE. Figure 5a compares the Li ions plating/stripping behaviors of SPCE with $\mathrm{LiNO}_{3}$ addition and SPCE without $\mathrm{LiNO}_{3}$ addition with $\mathrm{Li} \mid$ I Li symmetric batteries at $0.1 \mathrm{~mA} \mathrm{~cm}{ }^{-2}$. The overpotential of $\mathrm{Li}$ | I $\mathrm{Li}$ cells using SPCE without $\mathrm{LiNO}_{3}$ increases with the increase in the cycle number, and a short-circuit occurred after $150 \mathrm{~h}$ of cycling. In contrast, the initial voltage of $\mathrm{Li}$ | I Li cells using SPCE with $\mathrm{LiNO}_{3}$ is only $18 \mathrm{mV}$ and the battery can maintain a stable voltage cycle more than $500 \mathrm{~h}$. The results confirm that SPCE with $\mathrm{LiNO}_{3}$ and Li metal have good interface stability. Figure 5b shows that Li ISPCE I Li has good cycle stability at different current densities, even at $0.5 \mathrm{~mA} \mathrm{~cm}{ }^{-2}$. By comparison of the nyquist plots before and after cycling at different rates (Figure $5 c$ ), we can see that the interface contact between electrolyte and Li metal (represented from the first arc of EIS curve) is not very good at beginning but becomes better after cycling. It further proves the excellent compatibility of SPCE with Li metal. 

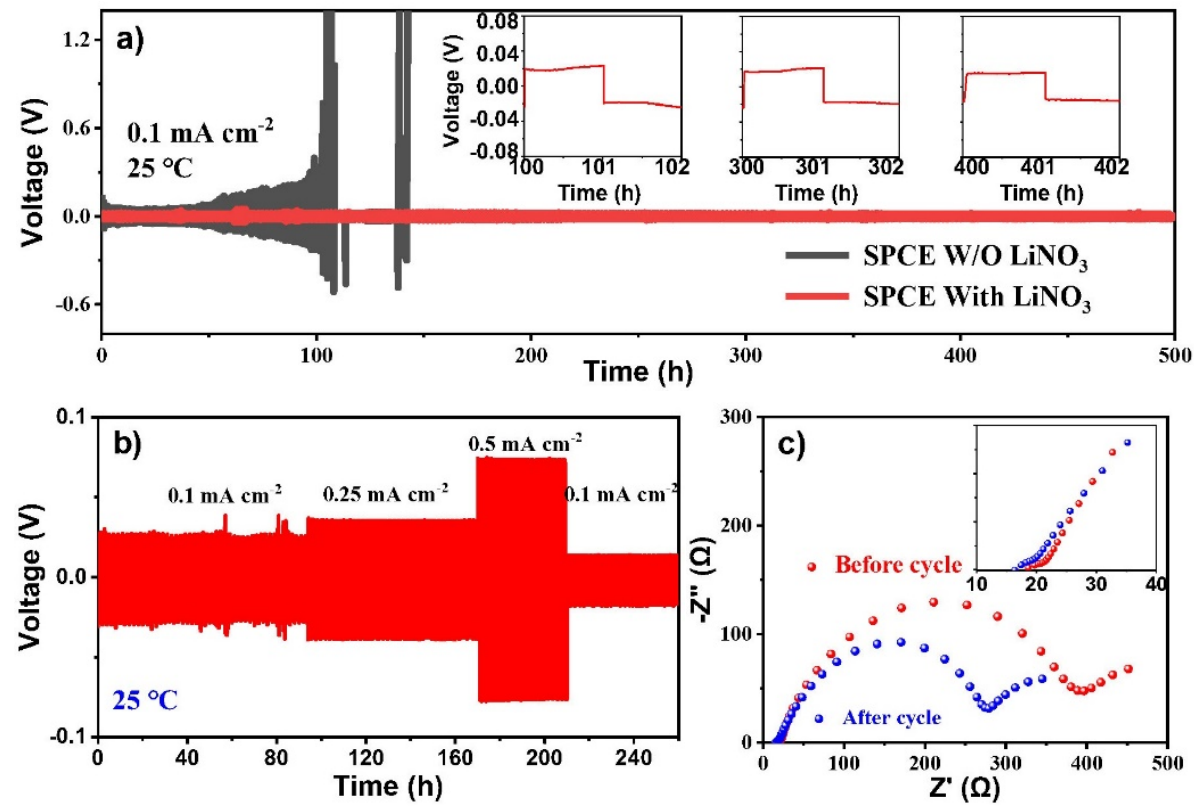

Figure 5. Electrochemical performance of Li ISPCE I Li cell. (a) Cycling curves of SPCE with and without $\mathrm{LiNO}_{3}$ additive. (b) Cycling curves of SPCE film at different rate and (c) EIS test before and after the cycle test in (b).

\section{3. $\mathrm{LiFePO}_{4}||$ Li Solid-State Cell Performance}

For solid state batteries, interface between solid cathode particles and solid electrolyte is also a big challenge due to the solid-solid contact. SN has a low melting point, and it can be injected into cathode directly without solvent. Additionally, SN-based SPCEs have a plasticity nature, resulting in a good interface between cathode particles and solid electrolyte. So, it is an effective strategy to assemble solid state batteries all based on SPCEs, and the structure is illustrated in Figure 6a. Figure $6 \mathrm{~b}$ shows the charge and discharge curves of $\mathrm{LiFePO}_{4}|\mathrm{SPCE}| \mathrm{Li}$ after the $1 \mathrm{st}, 20 \mathrm{th}, 50 \mathrm{th}$, and 80 th cycles at $0.5 \mathrm{C}$. As the number of cycling times increase, tiny polarization can be found for the $\mathrm{LiFePO}_{4}|\mathrm{SPCE}| \mathrm{Li}$ cell, which proves good interface characteristics. The cycling performance of $\mathrm{LiFePO}_{4}|| \mathrm{Li}$ battery is shown in Figure 6c; the electrochemical reaction of charge process can be described as: $\mathrm{LiFePO}_{4}-x \mathrm{Li}^{+}-x e^{-} \rightarrow x \mathrm{FePO}_{4}+(1-x) \mathrm{LiFePO}_{4}$. The initial charge capacity of the battery with the SPCE is as high as $121.4 \mathrm{mAh} \mathrm{g}^{-1}$ at $0.5 \mathrm{C}$, and the capacity is $105.5 \mathrm{mAh} \mathrm{g}^{-1}$ after 90 cycles; the first-cycle coulombic efficiency is $93.74 \%$ and is always maintained at over $97 \%$ after the 6th cycle, which shows that $\mathrm{LiFePO}_{4}$ has good contact with SPCE and good cycle stability. The relatively low first-cycle coulombic efficiency is mainly due to the unstable initial interface of SPCE with $\mathrm{Li}$ anode, which is consist with Li | | Li cycling data in Figure 5. The wettability of SN based SPCE electrolyte is not so good, as we have mentioned in the experiment section, cathode electrode needs to be dipped into solution at $60{ }^{\circ} \mathrm{C}$ for $12 \mathrm{~h}$ to let electrolyte solution infused into the electrode. So, the slow degradation of the capacity may be caused by the interface fading between electrode material and solid electrolyte during cycling. Figure $6 \mathrm{~d}$ shows that the capacity of $\mathrm{LiFePO}_{4} \mid \mathrm{SPCE}$ | $\mathrm{Li}$ at $0.2 \mathrm{C}, 0.5 \mathrm{C}$, and $1 \mathrm{C}$ is $147.1 \mathrm{mAh} \mathrm{g}^{-1}, 137.8 \mathrm{mAh} \mathrm{g}^{-1}$, and $102.3 \mathrm{mAh} \mathrm{g}^{-1}$, respectively. When the solid-state battery returns from $1 \mathrm{C}$ to $0.2 \mathrm{C}$, the charge capacity can still be maintained at $141.4 \mathrm{mAh} \mathrm{g}^{-1}$. These results demonstrate that the $\mathrm{LiFePO}_{4}$ ISPCE I Li cell possesses excellent rate performance, which is attributed to the good interfacial stability between electrolyte and both cathode and Li anode. Figure $6 \mathrm{~d}$ shows the charge-discharge voltage curves of LFP I SPCE I Li battery at different rates. The small voltage polarization of the battery can provide good electrochemical reversibility for the battery reaction. 
a)

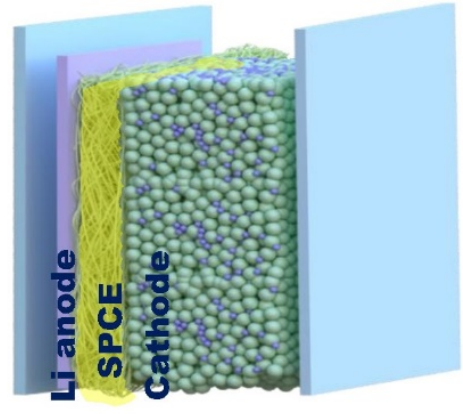

b)

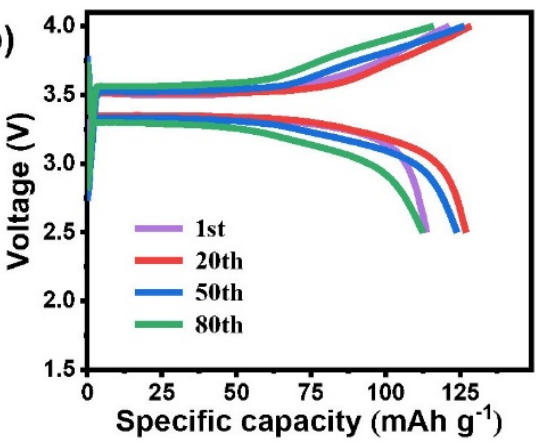

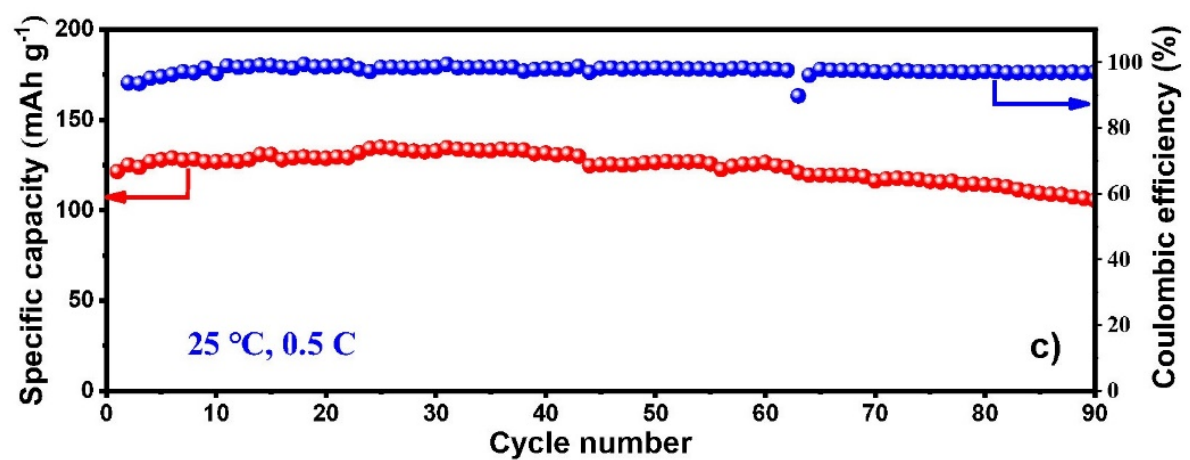

d)
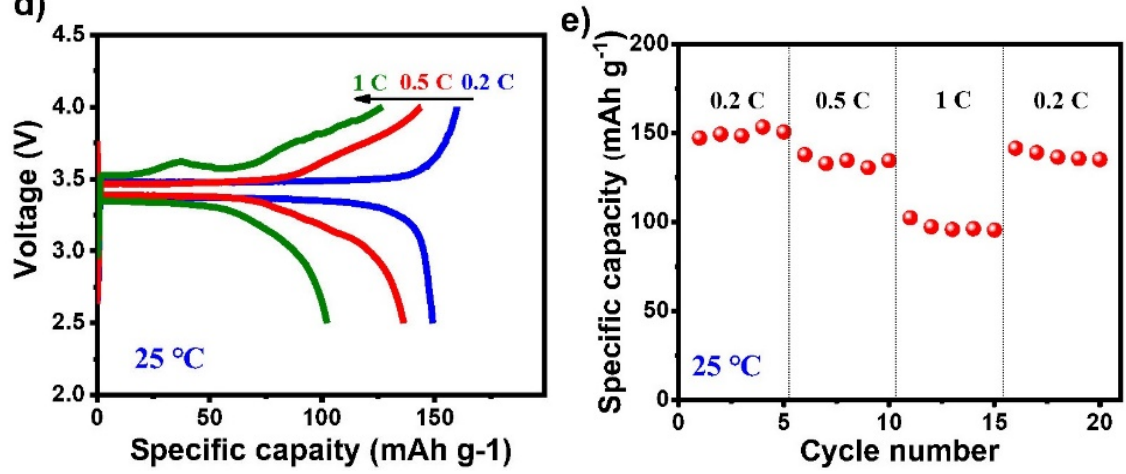

Figure 6. (a) Schematic diagram of the structure of $\mathrm{LiFePO}_{4} \mid$ | Li solid-state battery. (b) Voltage profile at different cycles. (c) Long-term cycling performance at $0.5 \mathrm{C}$. (d) Voltage profiles at different cycling rate. (e) Rate performance of the cell. All results are collected at room temperature.

\section{Summary}

In summary, SPCE is proved to be an effective ambient-temperature solid electrolyte for all solid-state Li-metal batteries. For the SPCE film, commercial glass fiber film is introduced as the framework to improve mechanical properties. The ionic conductivity of the SPCE film is as high as $7.3 \times 10^{-4} \mathrm{~S} \mathrm{~cm}^{-1}$ at room temperature. Furthermore, with $\mathrm{LiNO}_{3}$ additive, the SPCE have a good contact surface with lithium metal and excellent mechanical properties, which can enable the symmetrical Li I I Li cell to stably cycle more than $500 \mathrm{~h}$ at $0.1 \mathrm{~mA} \mathrm{~cm}^{-2}$. More importantly, SPCE shows excellent cycle stability and superior rate performance in $\mathrm{LiFePO}_{4}||$ | Li solid-state battery, where SPCE also serves as an interface between cathode and SPCE film. Thus, based on our research, the design of all solid-state batteries based on SPCEs is feasible. For a more practical application, more optimizations may need to be studied, such as searching for a more effective 3D framework to obtain an ultrathin SPCE film or finding other additives to substitute $\mathrm{LiNO}_{3}$, etc. 
Supplementary Materials: The following are available online at https: / www.mdpi.com/article/ 10.3390/en14216946/s1, Figure S1: Photograph of pure SPCE, Figure S2: SEM image of glass fiber film, Figure S3: SEM image of cross section of SPCE film, Figure S4: Photographs of SPCE film, Figure S5: Schematic diagram of the structure of SN doped with LiTFSI salt, Figure S6: LSV curve with SS I SPCE I Li cell.

Author Contributions: Conceptualization, B.Z.; Data curation, X.H.; Formal analysis, B.Z.; Funding acquisition, B.Z. and X.H.; Investigation, Q.W.; Methodology, B.Z.; Project administration, X.H.; Resources, X.H.; Software, B.Y.; Supervision, X.H.; Validation, B.Z., Q.W. and Y.L.; Visualization, B.Z.; Writing—original draft, Q.W.; Writing—review and editing, B.Z. All authors have read and agreed to the published version of the manuscript.

Funding: This research was funded by National Key R\&D Program of China (Grant No. 2018YFB0104300), National Natural Science Foundation of China (Grant No. 51707151), National Natural Science Foundation of China (Grant No. 51772241).

Institutional Review Board Statement: Not applicable.

Informed Consent Statement: Not applicable.

Data Availability Statement: Not applicable.

Acknowledgments: X. Han would like to thank the Independent Research Project of State Key Laboratory of Electrical Insulation and Power Equipment for the financial support. B. Zhao acknowledge the State Key Laboratory of Electrical Insulation and Power Equipment for financial support.

Conflicts of Interest: The authors declare no conflict of interest.

\section{References}

1. Harper, G.; Sommerville, R.; Kendrick, E.; Driscoll, L.; Slater, P.; Stolkin, R.; Walton, A.; Christensen, P.; Heidrich, O.; Lambert, S.; et al. Recycling lithium-ion batteries from electric vehicles. Nature 2019, 575, 75-86. [CrossRef]

2. Armand, M.; Tarascon, J.M. Building better batteries. Nature 2008, 451, 652-657. [CrossRef] [PubMed]

3. Pramanik, A.; Maiti, S.; Mahanty, S. Superior lithium storage properties of Fe-2(MoO 4$)(3) / \mathrm{MWCNT}$ composite with a nanoparticle (0D)-nanorod (1D) hetero-dimensional morphology. Chem. Eng. J. 2017, 307, 239-248. [CrossRef]

4. Pramanik, A.; Maiti, S.; Mahanty, S. Metal hydroxides as a conversion electrode for lithium-ion batteries: A case study with a $\mathrm{Cu}(\mathrm{OH})(2)$ nanoflower array. J. Mater. Chem. A 2014, 2, 18515-18522. [CrossRef]

5. Nitta, N.; Wu, F.; Lee, J.T.; Yushin, G. Li-ion battery materials: Present and future. Mater. Today 2015, 18, 252-264. [CrossRef]

6. Lu, J.; Chen, Z.; Pan, F.; Cui, Y.; Amine, K. High-performance anode materials for rechargeable lithium-ion batteries. Electrochem. Energ. Rev. 2018, 1, 35-53. [CrossRef]

7. Xiao, J.; Li, Q.; Bi, Y.; Cai, M.; Dunn, B.; Glossmann, T.; Liu, J.; Osaka, T.; Sugiura, R.; Wu, B.; et al. Understanding and applying coulombic efficiency in lithium metal batteries. Nat. Energy 2020, 5, 561-568. [CrossRef]

8. Zhang, F.; Shen, F.; Fan, Z.-Y.; Ji, X.; Zhao, B.; Sun, Z.-T.; Xuan, Y.-Y.; Han, X.-G. Ultrathin $\mathrm{Al}_{2} \mathrm{O}_{3}$-coated reduced graphene oxide membrane for stable lithium metal anode. Rare Metals 2018, 37, 510-519. [CrossRef]

9. Liu, Q.; Zhou, S.; Tang, C.; Zhai, Q.; Zhang, X.; Wang, R. Li-B alloy as an anode material for stable and long life lithium metal batteries. Energies 2018, 11, 2512. [CrossRef]

10. Zhao, Q.; Stalin, S.; Zhao, C.-Z.; Archer, L.A. Designing solid-state electrolytes for safe, energy-dense batteries. Nat. Rev. Mater. 2020, 5, 229-252. [CrossRef]

11. Wan, J.; Xie, J.; Mackanic, D.G.; Burke, W.; Bao, Z.; Cui, Y. Status, promises, and challenges of nanocomposite solid-state electrolytes for safe and high performance lithium batteries. Mater. Today Nano 2018, 4, 1-16. [CrossRef]

12. Lim, Y.S.; Jung, H.-A.; Hwang, H. Fabrication of PEO-PMMA-LiClO4-based solid polymer electrolytes containing silica aerogel particles for all-solid-state lithium batteries. Energies 2018, 11, 2559. [CrossRef]

13. Cheng, Z.; Liu, T.; Zhao, B.; Shen, F.; Jin, H.; Han, X. Recent advances in organic-inorganic composite solid electrolytes for all-solid-state lithium batteries. Energy Stor. Mater. 2021, 34, 388-416. [CrossRef]

14. Zhao, Y.; Wang, L.; Zhou, Y.; Liang, Z.; Tavajohi, N.; Li, B.; Li, T. Solid polymer electrolytes with high conductivity and transference number of Li ions for Li-based rechargeable batteries. Adv. Sci. 2021, 8, 2003675. [CrossRef]

15. Zhang, Q.; Liu, K.; Ding, F.; Liu, X. Recent advances in solid polymer electrolytes for lithium batteries. Nano Res. 2017, 10, 4139-4174. [CrossRef]

16. Wei, Z.; Zhang, Z.; Chen, S.; Wang, Z.; Yao, X.; Deng, Y.; Xu, X. UV-cured polymer electrolyte for $\mathrm{LiNi}_{0.85} \mathrm{Co}_{0.05} \mathrm{Al}_{0.1} \mathrm{O}_{2} / / \mathrm{Li} \mathrm{solid}$ state battery working at ambient temperature. Energy Stor. Mater. 2019, 22, 337-345. [CrossRef]

17. Long, S.; MacFarlane, D.R.; Forsyth, M. Fast ion conduction in molecular plastic crystals. Solid State Ionics 2003, 161, 105-112. [CrossRef] 
18. Alarco, P.J.; Abu-Lebdeh, Y.; Abouimrane, A.; Armand, M. The plastic-crystalline phase of succinonitrile as a universal matrix for solid-state ionic conductors. Nat. Mater. 2004, 3, 476-481. [CrossRef] [PubMed]

19. Abouimrane, A.; Abu-Lebdeb, Y.; Alarco, P.J.; Armand, M. Plastic crystal-lithium batteries: An effective ambient temperature all-solid-state power source. J. Electrochem Soc. 2004, 151, A1028-A1031. [CrossRef]

20. Tong, Z.; Wang, S.-B.; Fang, M.-H.; Lin, Y.-T.; Tsai, K.-T.; Tsai, S.-Y.; Yin, L.-C.; Hu, S.-F.; Liu, R.-S. Na-CO 2 battery with NASICON-structured solid-state electrolyte. Nano Energy 2021, 85, 105972. [CrossRef]

21. Niu, W.; Chen, L.; Liu, Y.; Fan, L.-Z. All-solid-state sodium batteries enabled by flexible composite electrolytes and plastic-crystal interphase. Chem. Eng. J. 2020, 384, 123233. [CrossRef]

22. Gao, H.; Xue, L.; Xin, S.; Park, K.; Goodenough, J.B. A plastic-crystal electrolyte interphase for all-solid-state sodium batteries. Angew. Chem. Int. Ed. 2017, 56, 5541-5545. [CrossRef]

23. Wei, T.; Zhang, Z.-H.; Wang, Z.-M.; Zhang, Q.; Ye, Y.-S.; Lu, J.-H.; Rahman, Z.U.; Zhang, Z.-W. Ultrathin solid composite electrolyte based on $\mathrm{Li}_{6.4} \mathrm{La}_{3} \mathrm{Zr}_{1.4} \mathrm{Ta}_{0.6} \mathrm{O}_{12} / \mathrm{PVDF}-\mathrm{HFP} / \mathrm{LiTFSI} /$ succinonitrile for high-performance solid-state lithium metal batteries. ACS Appl. Energy Mater. 2020, 3, 9428-9435. [CrossRef]

24. Pal, P.; Ghosh, A. Robust succinonitrile plastic crystal-based Ionogel for all-solid-state Li-ion and dual-ion batteries. ACS Appl. Energy Mater. 2020, 3, 4295-4304. [CrossRef]

25. Liang, W.; Shao, Y.; Chen, Y.-M.; Zhu, Y. A 4 V cathode compatible, superionic conductive solid polymer electrolyte for solid lithium metal batteries with long cycle life. ACS Appl. Energy Mater. 2018, 1, 6064-6071. [CrossRef]

26. Jiang, T.; He, P.; Wang, G.; Shen, Y.; Nan, C.-W.; Fan, L.-Z. Solvent-free synthesis of thin, flexible, nonflammable garnet-based composite solid electrolyte for all-solid-state lithium batteries. Adv. Energy Mater. 2020, 10, 1903376. [CrossRef]

27. Choi, K.-H.; Cho, S.-J.; Kim, S.-H.; Kwon, Y.H.; Kim, J.Y.; Lee, S.-Y. Thin, deformable, and safety-reinforced plastic crystal polymer electrolytes for high-performance flexible lithium-ion batteries. Adv. Funct. Mater. 2014, 24, 44-52. [CrossRef]

28. Lu, Z.; Yu, J.; Wu, J.; Effat, M.B.; Kwok, S.C.T.; Lyu, Y.; Yuen, M.M.F.; Ciucci, F. Enabling room-temperature solid-state lithiummetal batteries with fluoroethylene carbonate-modified plastic crystal interlayers. Energy Stor. Mater. 2019, 18, 311-319. [CrossRef]

29. Hu, Z.; Xian, F.; Guo, Z.; Lu, C.; Du, X.; Cheng, X.; Zhang, S.; Dong, S.; Cui, G.; Chen, L. Nonflammable nitrile deep eutectic electrolyte enables high-voltage lithium metal batteries. Chem. Mater. 2020, 32, 3405-3413. [CrossRef]

30. Wang, C.; Adair, K.R.; Liang, J.; Li, X.; Sun, Y.; Li, X.; Wang, J.; Sun, Q.; Zhao, F.; Lin, X.; et al. Solid-state plastic crystal electrolytes: Effective protection interlayers for sulfide-based all-solid-state lithium metal batteries. Adv. Funct. Mater. 2019, $29,1900392$. [CrossRef]

31. Zhao, Q.; Liu, X.; Stalin, S.; Khan, K.; Archer, L.A. Solid-state polymer electrolytes with in-built fast interfacial transport for secondary lithium batteries. Nat. Energy 2019, 4, 365-373. [CrossRef] 